\section{EMBRYARIDDLE \\ Aeronautical University}

SCHOLARLY COMMONS
International Journal of Aviation, Aeronautics, and Aerospace

$11-17-2014$

\title{
Achieving global range in future subsonic and supersonic airplanes
}

Nihad E. Daidzic Ph.D., Sc.D.

AAR Aerospace Consulting, LLC, aaraerospace@cs.com

Follow this and additional works at: https://commons.erau.edu/ijaaa

Part of the Aerodynamics and Fluid Mechanics Commons, Aeronautical Vehicles Commons, Navigation, Guidance, Control and Dynamics Commons, Propulsion and Power Commons, Structures and Materials Commons, and the Systems Engineering and Multidisciplinary Design Optimization Commons

\section{Scholarly Commons Citation}

Daidzic, N. E. (2014). Achieving global range in future subsonic and supersonic airplanes. International Journal of Aviation, Aeronautics, and Aerospace, 1(4). https://doi.org/10.15394/ijaaa.2014.1038

This Article is brought to you for free and open access by the Journals at Scholarly Commons. It has been accepted for inclusion in International Journal of Aviation, Aeronautics, and Aerospace by an authorized administrator of Scholarly Commons. For more information, please contact commons@erau.edu. 
Cruise is the most economical phase of an airplane flight. Cruising aircraft is in a quasi-steady state and any change, such as weight loss due to fuel burn, is gradual. On ultra-long distances cruise consumes $90 \%$ of the entire flight duration. A standard IFR vertical flight profile that includes ATC delays and holding and takes into account company-specific and regulatory fuel and reserves (e.g., 14 CFRs $§ 121.639$ and $§ 121.645$ ) is illustrated in Figure 1.

Typically, range and endurance are the most important cruise performance parameters. Endurance or loiter is only important in some specialized missions (reconnaissance, sightseeing round trips, refueling aircraft, etc.) where duration, and not range, of flight is the primary performance goal. The Specific Air Range (SAR) is the essential cruise parameter defined as, $S A R=N M /($ lb fuel $)$. It is usually used in air-transportation industry as a number of NM (or NAM for nautical air miles) flown in still-air for each $1000 \mathrm{lb}$ of fuel (about 150 gallons of jet fuel). Modern narrow-body airplane-engine combinations will cruise today typically at SARs between 50 and $90 \mathrm{NAM} /(1000 \mathrm{lb}$ fuel). For wide-body that would be about $20-40 \mathrm{NAM} /(1000 \mathrm{lb}$ fuel) considering that it may carry three times the number of passengers and more cargo load. As the in-flight airplane weight decreases due to fuel burn (FC), SAR will increase as illustrated in Figure 2. Alternatively, SAR can be defined as $T A S / F C$ or $T A S /(S F C \times D)$, or by using the range factor $(\mathrm{RF}), R F=(T A S / S F C) \times(L / D)$. The $\mathrm{RF}$ is practically independent of the altitude and the weight in cruise-climb (Saarlas, 2007) and addresses only the essential airframe-engine performance parameters. Here, SFC is the specific fuel consumption (lb/hr fuel per lb thrust) which enables comparison of engines of different sizes and thrust ratings in terms of propulsive efficiency. SAR is maximized by flying high (increased TAS and/or M), having low SFC, and high fuel-weight-ratio. The total air range is obtained by integrating the weightdependent SAR over weight changes during cruise (approximately from TOW to $\mathrm{ZFW}+$ fuel reserves). SAR does not address the effect of wind. In that case the SGR (specific ground range) is used and particularly in conjunction with the Flight Management System (FMS), cost index (CI), and ECON cruise mode. Higher SAR implies longer range which is significant for long-distance flights, but more importantly it means that for a fixed route distance less fuel will be consumed thus increasing the economy of operation.

An airplane should be able to fly non-stop a minimum of 11,000 NAM to achieve the global range (GR). If wind, required fuel reserves, and almost inevitable deviations from the Great Circle (GC) routes are accounted for, the maximum cruise range (MRC) of approximately 12,500 NAM is needed. The prospect of spending 23+ hours in an airplane on non-stop GR flights is not very attractive though. For some new airplane models of today it is advertised that they 
can fly non-stop ultra-long distances reaching and exceeding 9,000 NM still-air distances (e.g., A340-500, B777-200LR). That could consistently occur only with reduced payload and/or huge cruise mission fuel capacities (> $45 \%$ of the MSTOW). For example, Boeing advertises 300-passenger B777-200LR with a Maximum Structural Takeoff Weight (MSTOW) of 766,000 lb. It is powered by two GE90-115BL turbofans with $115,300 \mathrm{lb}$ or $512 \mathrm{kN}$ of static thrust each at SL ISA. B777-200LR, dubbed "Worldliner", was introduced in 2006. The maximum fuel weight is $361,500 \mathrm{lb}$ or amazing $47 \%$ of MSTOW with extra three optional fuel tanks (53,515 US Gallons). It delivers a maximum still-air cruise range of about 9,400 NM. This particular airplane type basically flies ground distance routes of around 8,000 NM and thus is still about $40 \%$ short of the GR. Although specific data are not given, in terms of passenger-nautical-miles per gallon (pnm/g) this is about $53 \mathrm{pnm} / \mathrm{g}$ (or seat-km/liter equivalent) and not much different from an older McDonnell Douglas DC-10 airplane. The availability of alternate airports along the route is regulated by the Title 14 CFRs $\$ 121.161$ and $\$ 121.162$ (FAA, 2014) for operations under the jurisdiction of FAA. Additionally, ETOPS AC 120-42B (FAA, 2008) provides guidance for obtaining the operational approval for "extended operation". Hence, ETOPS may still limit the GR of twin-jet aircraft if large bodies of water, Polar regions, or unpopulated areas are to be overflown (Wagenmakers, 1991).

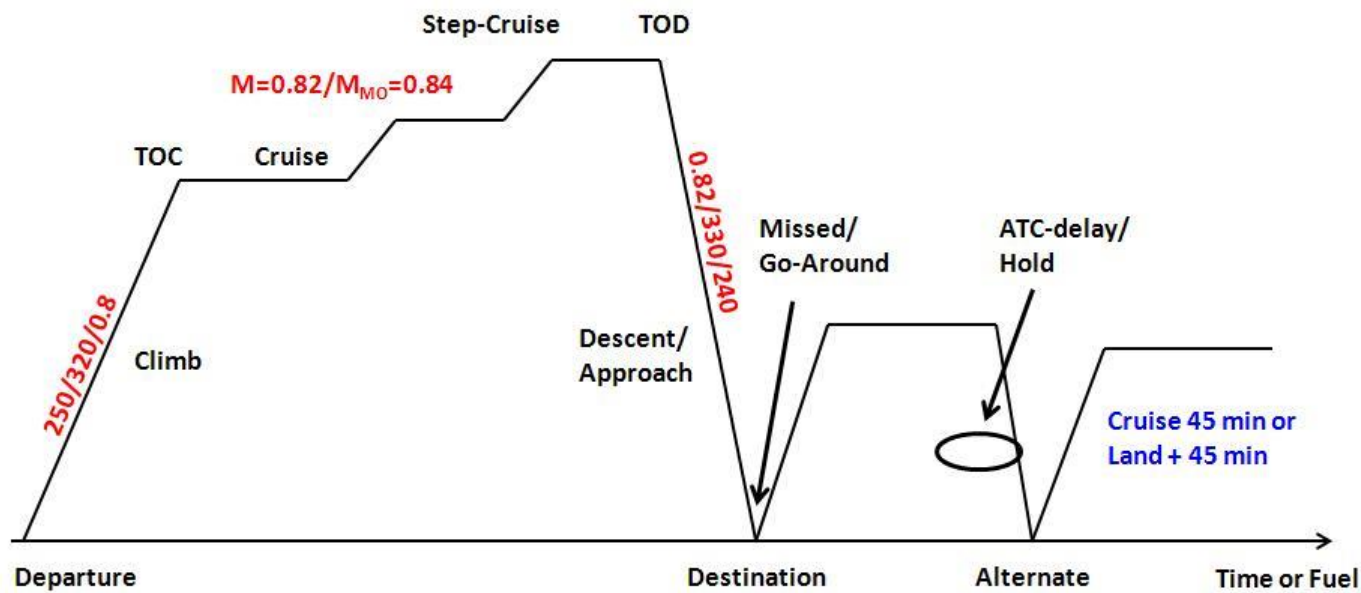

Figure 1. Standard IFR vertical flight profile for an arbitrary commercial transport-category (T-category) jetliner. Not to scale.

The supersonic transport (SST) achieves markedly shorter maximum ranges. However, due to significantly faster cruising speed it still flies around the globe (Concorde in 1992 and 1995 with 6 fuel stops. East and West) faster than any modern high-subsonic airplane would achieve with a single fuel-stop. British- 
French Concorde, unfortunately no longer in operational service, cruise-climbed (about $50 \mathrm{fpm}$ ) at $\mathrm{M}=2.0$ and altitudes between FL500 and FL600, thus staying just below the Armstrong limit (Daidzic \& Simones, 2010).

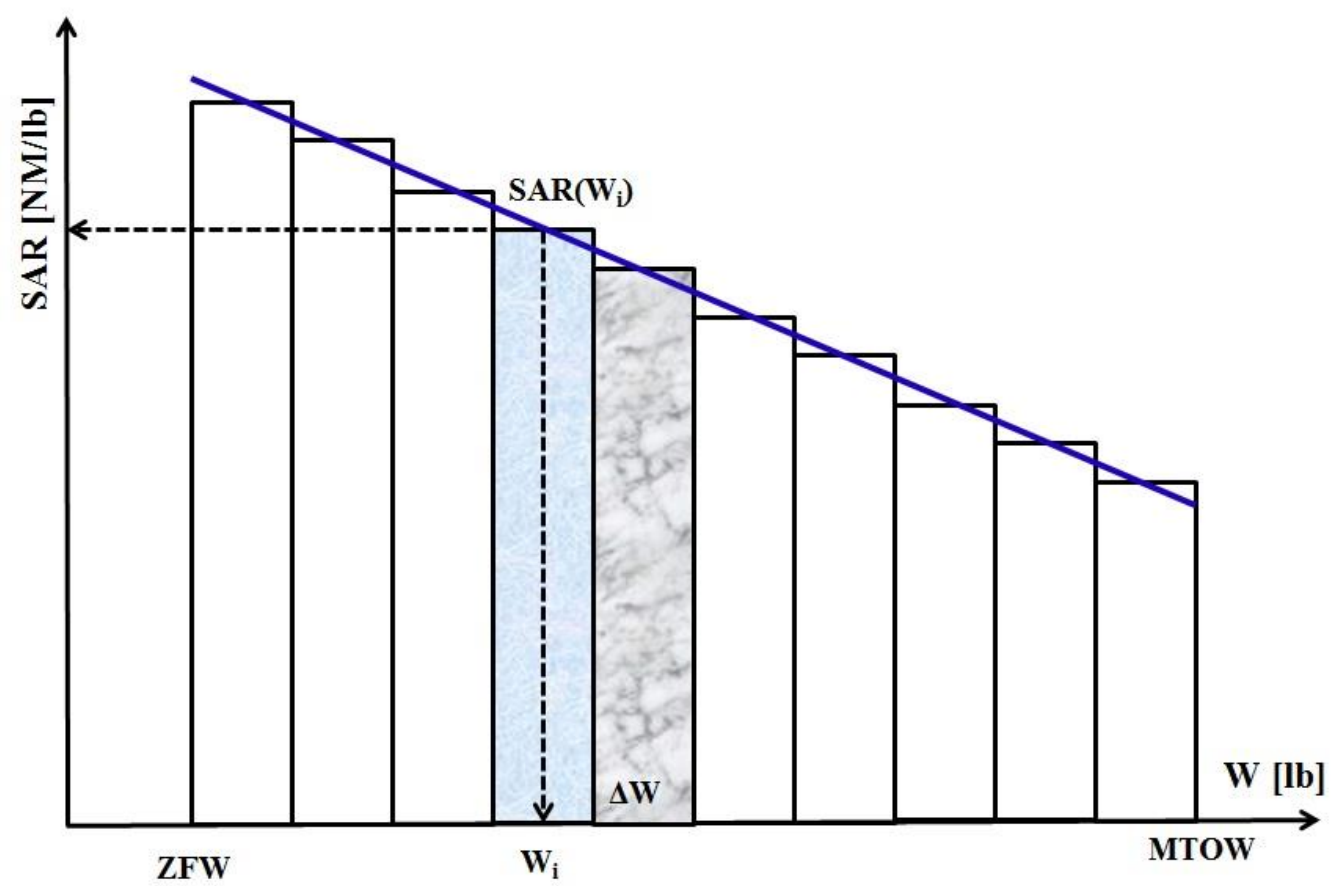

Figure 2. Specific air range as a function of weight. Range is calculated as a surface area under the SAR-Weight curve. Not to scale.

The Breguet's integral range equation was known for a long time. The range performance of airplanes is best summarized in many aeronautical engineering books some of which are referenced here. However, there is very little to none in peer-reviewed literature on the problem of achieving the GR. This comes as no surprise. Huge efforts in many fields of aeronautical, aerospace, and mechanical engineering, as well as in high-density fuels and thermochemistry are required to obtain GR in subsonic and supersonic aircraft. One unconventional idea of achieving GR is given in an article by Allen (2003) on "antipodal megaliner". It would carry more than 1,000 passengers and fly GC routes on trans-atmospheric trajectory. As Filippone (2006) also notes this is quite speculative and the aerospace industry is very conservative preferring little steps forward rather than revolutionary and untested designs. It is quite certain that large airplane manufacturer's, such as, Airbus and Boeing have conducted their own internal studies on global cruisers, but this is mostly proprietary information 
and not publically available. Achieving GR depends on the simultaneous advancements in many areas, such as, in the airplane structures, aerodynamics, and propulsion, which makes the entire issue very complex and uncertain.

The intent of this original research article is thus to provide a critical review of the cruise performance of subsonic and supersonic (SST) transportcategory aircraft based on the celebrated Breguet range equation while utilizing several fuel-flow laws, explore and compare the airframe-engine-atmospheric requirements, and identify and highlight some important scientific and technological developments needed for achieving GR.

\section{Cruise range theory}

When discussing the range of an aircraft one could start from the basic energy balance and thermodynamic (Brayton) cycle of a jet engine. Power available from the burning fuel is $P_{f}=\eta_{t h} H_{f} \dot{m}_{f}$ with the caloric (heating) value of most aviation JP fuels being about $43 \mathrm{MJ} / \mathrm{kg}$ or 18,500 Btu/lb (Davies, 2003; Hill \& Peterson, 1992; Lee, 2014; Mattingly, 2005: Treager, 1996; Ward, 2010). Having higher thermodynamic cycle efficiency $\left(\eta_{t h}\right)$ and utilizing high-density fuels (higher $H_{f}$ ) would substantially increase engine fuel efficiency (decrease SFC). Extracted power from fuel multiplied by mechanical and propulsive efficiencies results in the power available for propulsion $P_{a}=\eta_{m} \eta_{p} P_{f}=T_{a} \times V$.

Cruise starts at the completion of the climb phase top-of-climb (TOC) with some possible further acceleration to cruising airspeed/Mach number and ends at top-of-descent (TOD). Neglecting any control and trim forces on the conventional tail or canard surfaces, one may write for quasi-steady straight-andlevel flight (Hale, 1984):

$$
T=D \quad L=W \quad \frac{d X}{d t}=V \quad-\frac{d W}{d t}=S F C \times T=S F C \times D
$$

Since fuel is burned the aircraft weight change is negative. The reactive thrust component thrust force due to fuel burn rate is neglected. Although the balance of forces given by Equation 1 is approximate it still provides a wealth of information. Thrust required is directly proportional to the weight and indirectly proportional to the aerodynamic efficiency, $T=W / E$, where, $E=L / D=C_{L} / C_{D}$. The RF definition follows from the Equation 1: 


$$
R F=\frac{d X}{-d W / W}=\frac{V \cdot W}{S F C \cdot D}=\left(\frac{T A S}{S F C}\right) \cdot\left(\frac{L}{D}\right)=\frac{1}{S F C} \cdot \sqrt{\frac{2 \cdot W}{\sigma \rho_{S L} S}} \cdot\left(\frac{C_{L}^{1 / 2}}{C_{D}}\right)
$$

A still common misconception is that the MRC of jet airplanes is obtained when flying at $(L / D)_{\max }$ which corresponds to the minimum-drag speed $\left(V_{M D}\right)$ or at the AOA for maximum aerodynamic efficiency $\left(E_{\max }\right)$ and also known as glide ratio. Maximum range for jet airplane is actually obtained at speeds substantially higher than $V_{M D}$, typically in the range of $10 \%$ to $32 \%$ higher. This primarily depends on the cruise technique and the bypass-ratio (BPR) of turbofan engines. As Equation 2 clearly shows one needs to maximize $(V / S F C) \times(L / D)$ for each short segment of the cruise phase. The aerodynamic efficiency will change as a function of AOA, or airspeed in quasi-steady flight. Airspeed $V$ is TAS, and using the definition of the Mach number, one can write:

$$
S A R=\frac{R F}{W}=\left(M \frac{L}{D}\right) \cdot\left(\frac{a_{0} \times \theta^{1 / 2}}{S F C}\right) \cdot\left(\frac{1}{W}\right)=\frac{1}{S F C} \cdot \sqrt{\frac{2}{\sigma \rho_{S L} S}} \cdot\left(\frac{C_{L}^{1 / 2}}{C_{D}}\right) \cdot \frac{1}{\sqrt{W}}
$$

Knowing SAR, the cruise range can be obtained by integration over variable weight ( $M S T O W>W_{1}>W_{2}>Z F W$ ):

$$
R_{12}=-\int_{W_{1}}^{W_{2}} S A R(W) d W=\int_{W_{2}}^{W_{1}}\left(M \frac{L}{D}\right) \times\left(\frac{a_{0} \times \theta^{1 / 2}}{S F C}\right) \times \frac{d W}{W}
$$

Integration of Equation 4 is not trivial. It can be performed analytically only with many assumptions made first. This is usually sufficient for preliminary analysis. For accurate predictions, numeric integration is performed allowing all parameters to change as the flight progresses (Saarlas, 2007). Different cruise profiles exist during which altitude, airspeed, thrust, aerodynamic efficiency, etc., may change. One of the main obstacles in analytical integration of Equation 4 is that SFC is a function of temperature and Mach number (and other factors as well). Equation 4 is usually called Breguet range equation in honor of the famous French aviation designer Louis Charles Breguet (Anderson, 1999; Nicolai \& Carichner, 2010). The Breguet range equation will be typically accurate within 5$10 \%$ of the measured or numerically integrated still-air range in cruise-climb. It is only an approximation of the real aircraft performance. For example, the airplane's drag polar is not known exactly until measured and validated in test flights and wind-tunnel scale measurements. Eshelby (2000) describes the procedures and methods for cruise performance measurements and the airplane 
certification process. Padilla (1996) considers the effects of wind, altitude, and nonstandard-temperature on airplane cruise performance. Additionally, the performance aspects of fuel tankering, integrated cruise time, and calculating the point-of-no-return (PNR) is covered as well.

\section{Fuel-flow laws}

The most important efficiency parameter for any jet propulsive device is TSFC (thrust specific fuel consumption) or simply just SFC. It defines the amount of fuel $(\mathrm{lb} / \mathrm{hr}$ or $\mathrm{kg} / \mathrm{h})$ used for each unit of thrust (lbf or $\mathrm{N} / \mathrm{daN} / \mathrm{kN}$ ) produced (Asselin, 1997; Davies, 2003; Hill \& Peterson, 1992; Lee, 2014; Mattingly, 2005; McCormick, 1995; Padilla, 1996; Raymer, 1999; Treager, 1996; Ward, 2010).

In order to solve the general optimum cruise problem and maximize range it is important to know how SFC varies with variables such as altitude, air temperature and pressure, TAS/M, spool RPM $\left(\mathrm{N}_{1}\right.$ and/or $\left.\mathrm{N}_{2}\right)$, relative thrust, bypass-ratio, inlet RAM efficiency, and other less critical parameters. No general theory exists to describe this functional relationship for jet engine as numerous variables are influencing SFC. Different jet engines models, even those coming from the same manufacturer, will often exhibit somewhat different fuel-flow laws.

The only way to validate cruise range performance numbers (SAR, RF, SFC, $\mathrm{M}_{\mathrm{MRC}}$ ) for an airplane-engine combination is by performing repeated flight tests in instrumented prototypes (Eshelby, 2000). A myriad of environmental, engine-specific, flight and aerodynamic parameters are measured and processed to obtain approved cruise performance data for the Airplane Flight Manuals (AFM).

For preliminary cruise analysis of new airplane designs three fuel-flow laws are commonly used:

I. Constant SFC independent of altitude and Mach number or $S F C=S F C_{0}$.

II. SFC decreasing with temperature only or $S F C=S F C_{0} \times \theta^{1 / 2}$

III. SFC decreasing with altitude and increasing with Mach number, $S F C=S F C_{r e f} \times \theta^{1 / 2} \times M^{n}$. This expression is only valid in a limited range of Mach numbers (Mair \& Birdsall, 1992; Eshelby, 2000). 
For most high-bypass turbofans one can reasonably assume M-number exponent to be $n=0.48$ (Mair \& Birdsall, 1992), while Eshelby (2000) reports a value of $n=0.6$. Turbofan engines are most efficient at nominal RPMs of 90$95 \%$ and relative thrust of about $80 \%$ of maximum rated thrust although this is not true for every altitude and every engine (Daidzic, 2012). Exact numbers and specifications do change from turbofan to turbofan model and there is no substitute yet for actual ground and flight tests. Several fuel-flow laws for highand low-BPR turbofans, turbojets and turboprops are given by Mattingly (2005).

In the case of the first fuel-flow law with the constant SFC and assuming the constant-Mach cruise with the constant aerodynamic-efficiency (cruiseclimb), the Breguet range equation for jet airplane results in simple integration:

$R_{12}^{I}=-\int_{W_{1}}^{W_{2}} S A R(W) d W=\left(\frac{a_{S L} \times \theta^{1 / 2}}{S F C_{0}}\right) \times\left(M \frac{L}{D}\right) \times \ln (m r)$

where:

$m r=\frac{W_{1}}{W_{2}}=\frac{W_{1}}{W_{1}-W_{f}}=\frac{1}{1-\varsigma} \quad \varsigma=\frac{W_{f}}{W_{1}} \quad\left(W_{1} \approx T O W, W_{2} \approx Z F W+W_{F \text { Res }}\right)$

The first term in Equation 5 is just a constant for given temperaturealtitude. The MRC is thus achieved at the maximum $(M \times L / D)$ and the highest mass (or weight) ratio " $m r$ ". The coefficient $\varsigma$ is the fuel-weight ratio (FWR). The natural logarithm of the weight " $m r$ " ratio is fuel-ratio (FR) coefficient which determines how much of the RF will be translated into actual still-air range. At lower altitudes cruise Mach number is limited by $\mathrm{V}_{\mathrm{MO}}$ or dynamic-pressure limit (max-Q). Decreasing temperature with altitude also implies lower air pressures and densities and the increasing TAS for constant CAS/EAS. Maximum subsonic cruise airspeed (TAS) and altitude are limited by the maximum operating $\left(M_{M O}\right)$ or drag-divergence Mach number $\left(M_{C R}<M_{D D}\right)$, where onset of substantial wave drag increase begins. Coffin-corner defines the ultimate altitude-speed limit.

Since, in reality, SAR changes and depends on so many parameters, one can simply measure average SAR during small weight changes (e.g., for every $1000 \mathrm{lb}$ weight decrease due to fuel burned) in steady-state cruise and then numerically integrate Equation 3 (see also Figure 2): 


$$
R=\Delta W \times \sum_{i=1}^{N} S A R_{i}\left(M, E, \theta, \delta, S F C, W_{i}\right)
$$

Once SAR and the average wind over particular distance during which the airplane weight decreases is known, the SGR can be calculated for known Mach, temperature, and wind factor (WF):

$$
S G R=\frac{T A S \pm V_{W}}{S F C \times D}=S A R \times\left(1 \pm \frac{V_{W}}{a_{S L} \cdot \theta^{1 / 2} \cdot M}\right)=S A R \times W F
$$

More in-depth analysis of wind effects is given in Asselin (1997), Hale (1984), Padilla (1996), and Saarlas (2007). When headwind exists $(H W>0)$, resulting in $W F<1$.

The $2^{\text {nd }}$ fuel-flow law where SFC decreases with the temperature (altitude) level will result in cruise-climb MRC condition $\left(M_{M R C} \leq M_{D D}\right)$ :

$$
R_{12}^{I I}=-\int_{W_{1}}^{W_{2}} S A R(W) d W=\left(\frac{a_{S L}}{S F C_{0}}\right) \times\left(M \frac{L}{D}\right) \times \ln (m r)=R F \times \ln \left(\frac{W_{1}}{W_{2}}\right)
$$

While decreasing temperatures certainly reduce SFC $\left(R_{12}^{I I}>R_{12}^{I}\right)$ that will also lead to slower speeds of sound thereby lowering the maximum cruise TAS for constant maximum operating and/or drag-divergence Mach numbers.

The third fuel-flow law is the most complex of the three and the integration of the range equation for cruise-climb condition delivers:

$$
R_{12}^{I I I}=-\int_{W_{1}}^{W_{2}} S A R(W) d W=\left(\frac{a_{S L}}{S F C_{r e f}}\right) \times\left(M^{1-n} \frac{L}{D}\right) \times \ln (m r) \quad M_{M R C} \leq M_{D D}
$$

Here, $S F C_{r e f} \approx(1.5 \div 1.9) \cdot S F C_{0}$ at subsonic Mach numbers. Thus, $R_{12}^{\text {III }}<R_{12}^{I I}$ due to SFC increasing with the Mach number. An average value of $n=0.5$ was used here for modern high-BPR turbofans.

\section{Cruise techniques}

Essentially there are three "optimum" long-range cruise techniques: 
1. Flight at constant AOA (or $\mathrm{C}_{\mathrm{L}}$ ) and Mach number while altitude is increasing and is called cruise-climb technique.

2. Flight at constant altitude (FL) and AOA (or $\mathrm{C}_{\mathrm{L}}$ ) while Mach number is decreasing.

3. Flight at constant altitude (FL) and Mach number while AOA is decreasing as weight is decreasing.

Derivation of the analytical expressions for each of the three optimum range performances is given in Hale (1984) and Eshelby (2000) and will not be repeated here. In a first approximation lift must oppose aircraft weight in unaccelerated $n \approx 1$ (not to be confused with the BPR coefficient) level cruise flight:

$L=n \cdot W=\left(\frac{1}{2} p_{S L} \cdot \gamma\right) \cdot \delta \cdot M^{2} \cdot C_{L} \cdot S=1481.35 \cdot \delta \cdot M^{2} \cdot C_{L} \cdot S[\mathrm{lb}]$

Of these three cruise techniques, the absolute best range is achieved using the technique \#1 or the cruise-climb. As the airplane becomes lighter, in order to maintain constant AOA $\left(C_{L}\right)$ and $\mathrm{M}$ number, an airplane must slowly climb to reach lower atmospheric pressure-levels, $W / \delta \propto M^{2} \times C_{L}$.

Existing ATC system cannot allow an airplane climbing slowly, e.g., between FL330 and FL390, at crawling ROCs (10 to $20 \mathrm{fpm}$ ). It basically would take an order of an hour just to climb 1,000 feet. Obviously, there would also be a problem in indicating such miniscule climb rates. An airplane could be simply put in Mach-hold pitch mode. Auto-throttles should be engaged as the aerodynamic efficiency stays constant and the thrust required will decrease with the weight loss ( $T \propto W)$. According to Nicolai and Carichner (2010) the thrust will actually stay constant as some excess thrust is needed for shallow climb. Instead of cruiseclimb, the standard practice is to use the step-climb or stairs-climb so that airplane stays as close to the optimum altitude (FLoPT) as possible. Essentially, several discrete step-climbs will be performed over long-distance. Discrete step climbs in $2,000 \mathrm{ft}$ increments will reduce cruise-climb range by $2-3 \%$ (Hale, 1984). This is still superior compared to the other cruising techniques (\#2 or \#3). On short-tomedium flight distances, the cruising technique \#3 is typically the most appropriate. The cruise technique \#2, although simple and does not require altitude changes requires speed reductions which is often unacceptable 
considering the time-dependent operational cost, flight duration, and ATC restrictions. Very short flights are based on different optimization strategies.

Different step-climb techniques are shown in Figure 3. Besides optimumaltitude and number of steps an airplane is limited by the maximum thrust (propulsion) levels, the buffet-onset boundaries (BOB), ATC-restrictions, etc. In addition to the economy of operation pilots also have to worry about the airplane stability, control, and maneuverability. Typically, maximum flight altitudes will provide $1.3 \mathrm{~g}$ ( $40^{\circ}$ bank) maneuvering capability, while the optimum altitude (FLOPT) will provide minimum of $1.5 \mathrm{~g}$ ( $48^{0}$ bank angle) buffet margin protection.

The best economy is achieved by the vertical flight profile 2. More importantly best maneuverability and passenger comfort is achieved with the profile 1 . The vertical profile 3 provides reduced maneuverability and comfort margins and also worse economy than profiles 1 and 2 . Thus, profile 1, although not the most economical, provides the best overall flight conditions (Airbus, 1998). The fuel penalty for flying above FL OPT (e.g., 2,000 ft) is higher than when flying, say 2,000 ft, below FLOPT. The lower the CI, the higher the optimum altitude and at MRC condition maximum FLOPT is achieved. Generally, the higher the $\mathrm{CI}$ is the lower the optimum altitude and faster the airspeed is (typically $\mathrm{MMO}_{\mathrm{MO}^{-}}$ $0.02)$.

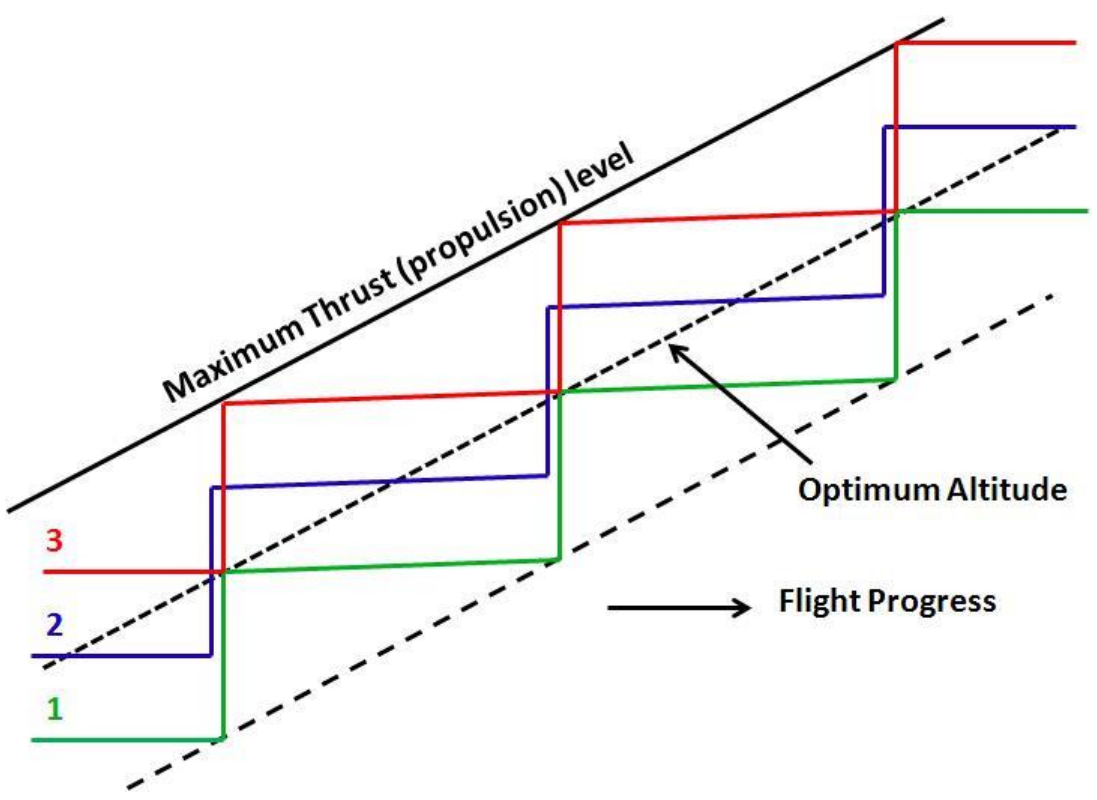

Figure 3. Different step-climb vertical profiles based on optimum and maximum propulsion altitudes. Not to scale. 


\section{Payload-range considerations}

A typical T-category airplane, certified under 14 CFR 25 (FAA, 2013), weight break-down and the payload-range diagram are shown in Figure 4. If an airplane accepts maximum payload limited by the Maximum Zero-Fuel Weight (MZFW) with no fuel, the range is zero. Adding fuel increases TOW and range while keeping the maximum payload. This can go until MSTOW is reached. Such is the best-case scenario and if the maximum-payload range is sufficient for the mission, the airplane operates most economically. The only way to increase range some more is to start replacing payload with fuel up to the maximum-fuel weight (maximum-fuel range) while keeping MSTOW constant. This reduces payload, but increases the maximum range (say from 5,000 to 6,000 NM). The only way to increase range even more (say now from 6,000 to maximum 6,500 NAM) is to actually keep the maximum fuel and start reducing payload. This payload reduction at maximum fuel decreases TOW until Empty/Basic Operating Weight (EOW/BOW) is reached which would be actually the ferry-range without additional fuel tanks. The reason range/SAR increases for the constant amount of maximum fuel is that induced drag is reduced. Clearly, this is not the mode of operation airlines would desire in regular revenue service (Wagenmakers, 1991).

\section{Great circle navigation}

The shortest distance between two points on Earth is the GC or the orthodrome. Earth is a special irregular oblate-spheroid called the Geoid which fairly accurately approximates equipotential MSL surface (Bowditch, 2002; Underdown \& Palmer, 2001; Wolper, 2001). The actual terrain elevation is given in relatively to vertical datum contained in WGS 84 spheroid. If for a moment Earth's small oblateness is neglected and a perfect sphere is assumed, then any GC will have arc-length of 21,600 NM (or about 40,000 km or 25,000 SM). In order for an airplane to achieve GR it should be able to fly non-stop half of any GC to a point which is exactly opposite on the Earth surface (antipodal points). Between two antipodal points there are infinitely GCs all of which have equal length assuming spherical earth. Utilizing the "law of cosine" (Bowditch, 2002; Wolper, 2001) from the spherical trigonometry considerations results in GC arclength $\left(\Delta \phi=\left|\phi_{1}-\phi_{2}\right|, \Delta \lambda=\left|\lambda_{1}-\lambda_{2}\right|\right)$ :

$$
L_{G C}=\bar{R}_{E} \cdot \cos ^{-1}\left(\sin \phi_{1} \cdot \sin \phi_{2}+\cos \phi_{1} \cdot \cos \phi_{2} \cdot \cos \Delta \lambda\right)
$$

Somewhat more stable orthodrome computations are obtained with the "haversine" form (Sinnott, 1984; Williams, 2011) of the spherical-Earth: 
$L_{G C}=2 \cdot \bar{R}_{E} \cdot \sin ^{-1}\left(\sqrt{\sin ^{2}\left(\frac{\Delta \phi}{2}\right)+\cos \phi_{1} \cdot \cos \phi_{2} \cdot \sin ^{2}\left(\frac{\Delta \lambda}{2}\right)}\right)$

Here, $\phi(\mathrm{N}+, \mathrm{S}-)$ is the latitude and $\lambda(\mathrm{W}+, \mathrm{E}-)$ is the longitude of the desired location on Earth. The average radius of the WGS 84 "Earth" is $6371 \mathrm{~km}$ (3440.06 NM). The error due to the actual spheroidal shape of the Earth is less than $0.5 \%$ and thus practically insignificant. All waypoints and headings of a GCroute can be calculated using the spherical trigonometry and the GC navigation calculations (Williams, 2011; Wolper, 2001).
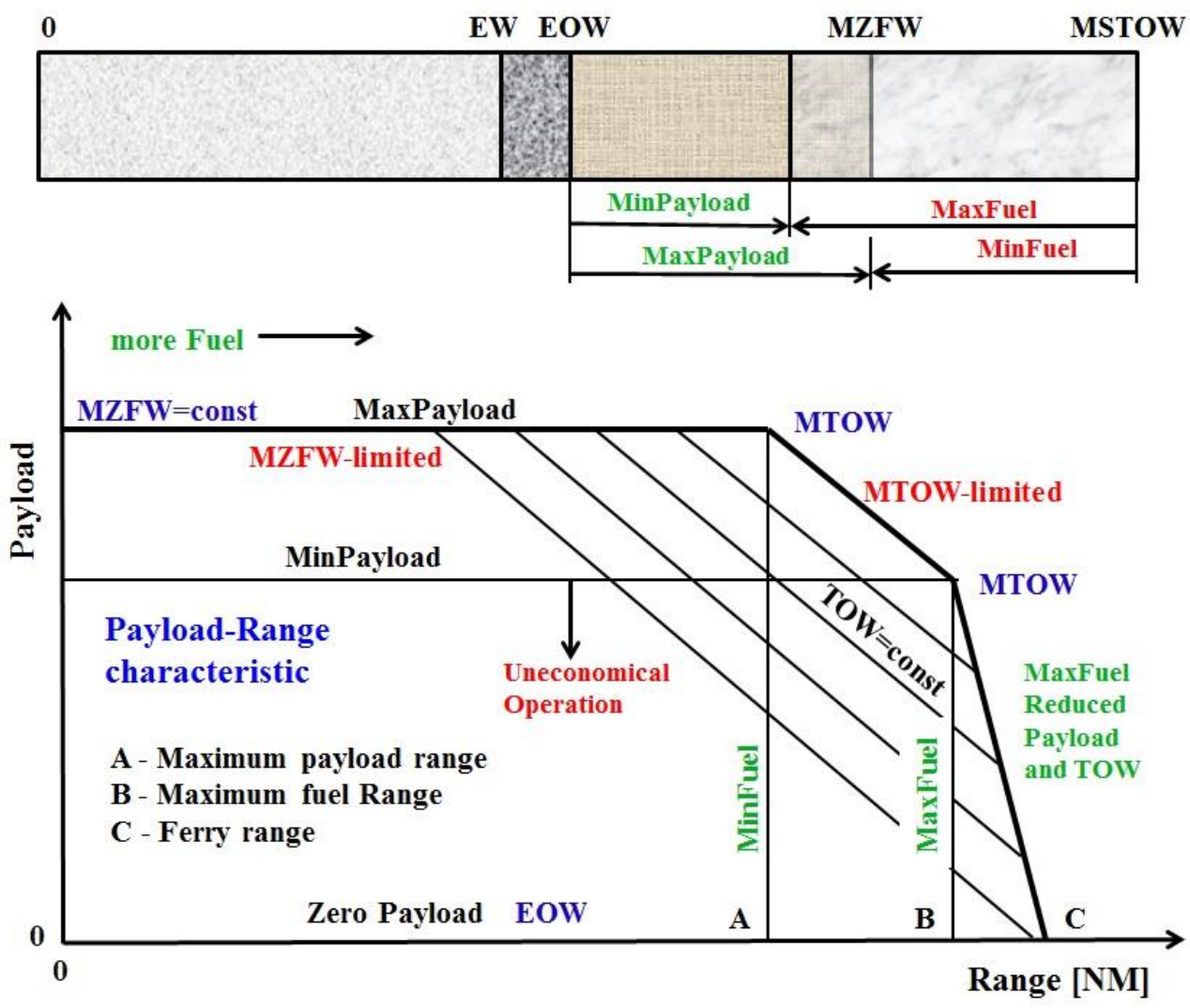

Figure 4. Weight break-down for a typical FAR/CS 25 airplane and payloadrange diagram. Not to scale.

\section{Cruise speed}

The best MRC condition is achieved at speed of about $32 \%$ above $\mathrm{V}_{\mathrm{MD}}$ when the SFC is speed-independent. The MRC speed is sometimes referred to as 
Carson's speed (Anderson, 1999). It can be easily shown (Anderson, 1999; Asselin, 1997; Davies, 2003; Eshelby, 2000; Hale, 1984; Mair \& Birdsall, 1992; McCormick, 1995; Vinh, 1993) that for the cruise-climb and the constant SFC, the MRC airspeed is obtained when drag-over-speed factor $(D / V)$ is minimized:

$V_{M R C}=3^{1 / 4} \cdot V_{M D}=1.316 \cdot V_{M D}$

Speeds for maximum range $\left(\mathrm{M}_{\mathrm{MRC}}\right)$ in variable wind situations, are illustrated in Figure 5. In headwind, the MRC-airspeed/Mach will have to increase leading to decreased range because of prolonged exposure to adverse wind and less-than-optimal aerodynamic conditions. The effect of weight on $V_{M D}$ and $V_{M R C} / M_{M R C}$ is shown in Figure 6. The lighter the airplane, both, the $V_{M D}$ and the $M_{M R C}$ move to the left, i.e., lower airspeeds. It is fairly easy to show that $V_{M R C} \propto \sqrt{W}$. More complicated expressions for MRC airspeed depending on the engine BPR's are given in Mair \& Birdsall (1992) and Eshelby (2000) and could be easily derived utilizing the $3^{\text {rd }}$ fuel-flow law:

$V_{M R C}(n)=\left(\frac{3-n}{1+n}\right)^{1 / 4} \cdot V_{M D}$

Another conclusion can be drawn from the engine BPR-factor " $n$ ". For pure turbojet's where " $n$ " approaches zero, the fuel-flow law is almost Machindependent and the MRC airspeed is close to $V_{M R C}=1.316 \times V_{M D}$. Indeed, this was the case for Concorde's turbojets. As the BPR increases and " $n$ " approaches one, the fuel-flow law is linearly dependent on Mach and the $V_{M R C}=V_{M D}$.

When the SFC is constant or depends only on temperature, MRC is achieved when the $\mathrm{RF}$ is maximized. This corresponds to the aerodynamic condition where, $C_{L}^{1 / 2} / C_{D}$, is maximum (and not where $E=L / D=C_{L} / C_{D}$ is maximum). The alternative expression for cruise-climb $\mathrm{MRC}$ with $S F C=S F C_{0}$ can be derived from the SAR definition given by Equation 3:

$$
R_{12}=\frac{2}{S F C_{0}} \times \sqrt{\frac{2}{\rho_{S L} S}} \times \sqrt{\frac{1}{\sigma}} \times\left(\frac{C_{L}^{1 / 2}}{C_{D}}\right) \times\left(W_{1}^{1 / 2}-W_{2}^{1 / 2}\right)
$$




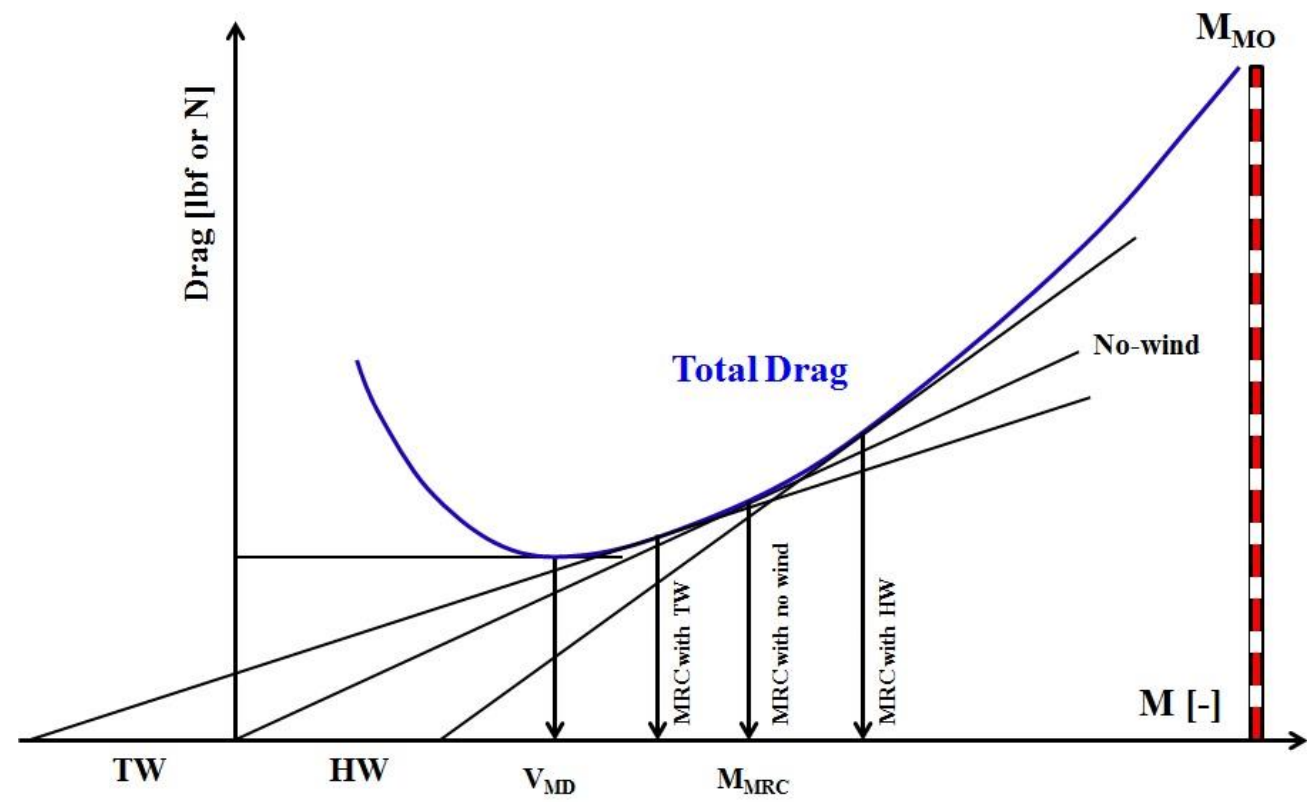

Figure 5. Maximizing range in no-wind and HW/TW situation. Not to scale.

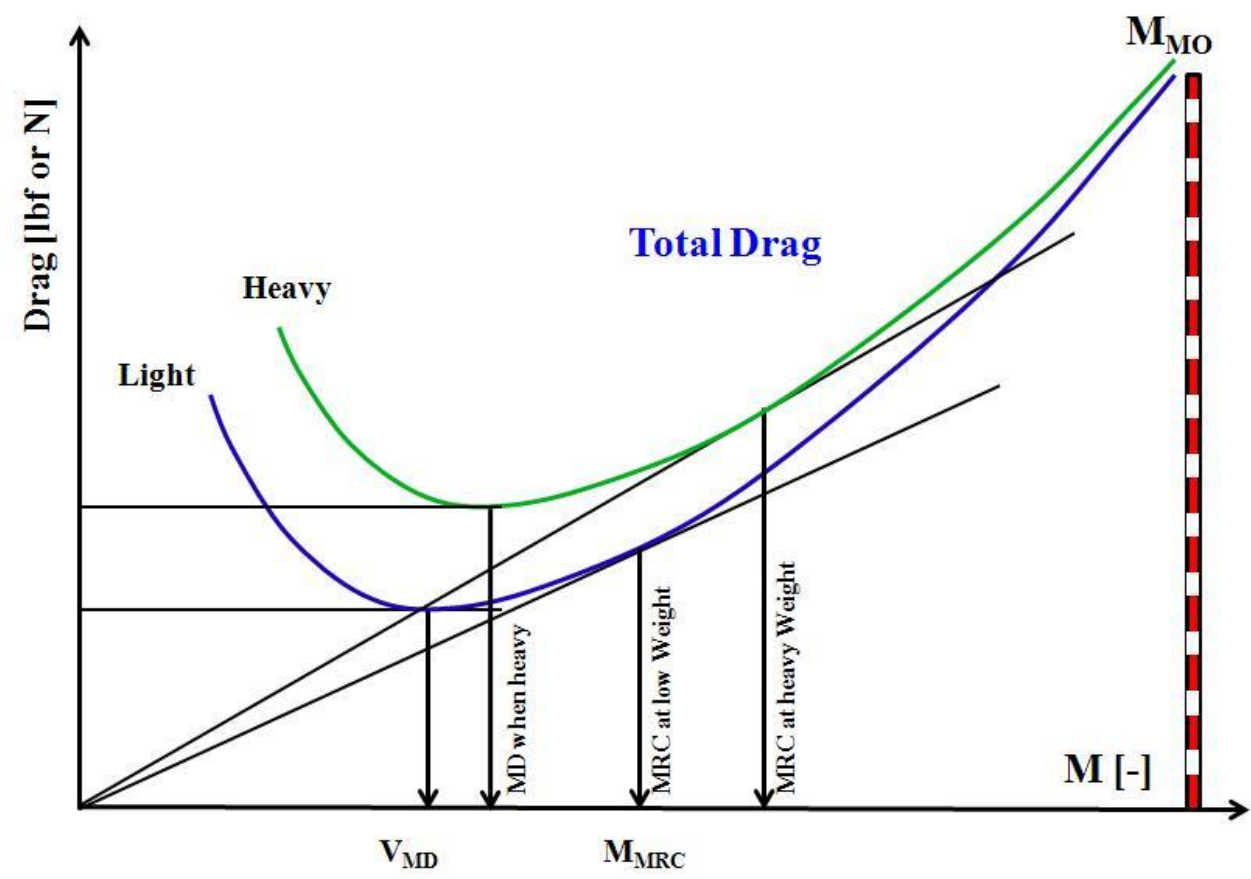

Figure 6. The effect of weight on minimum-drag and cruise speed at constant altitude. Not to scale. 
Density ratio $\sigma$ directly implies that flying at higher altitude increases the cruise range. The only time turbine-powered jet will achieve best range at maximum (L/D) is or with incredible tailwinds or when all engines flame out and airplane is inevitably descending at best-glide speed (for given in-flight weight). Only in such condition airframe aerodynamics alone drives the range considerations. In reality, since the SFC increases with Mach number and depends on turbofan BPR (Eshelby 2000), the MRC speeds are typically $10 \%$ to $25 \%$ above corresponding $\mathrm{V}_{\mathrm{MD}}$ (Equation 14). For example, if $\mathrm{M}_{\mathrm{MD}}$ for a given airplane is 0.7 then $\mathrm{M}_{\mathrm{MRC}}$ could be about 0.8 in high-BPR turbofan.

Four basic speed-schedules are used in modern FMS-equipped airplanes: MRC, LRC, ECON, and fixed-Mach schedules as illustrated in Figure 7. The MRC speeds can be obtained by choosing $\mathrm{CI}=0$ in which case there will be compensation for wind to maximize SGR which in direct (non-ECON) MRC mode is typically not possible. The LRC mode typically also does not incorporate wind compensation. On the other hand, ECON cruise mode takes into account existing winds and calculates airspeed based on the chosen $\mathrm{CI}$.

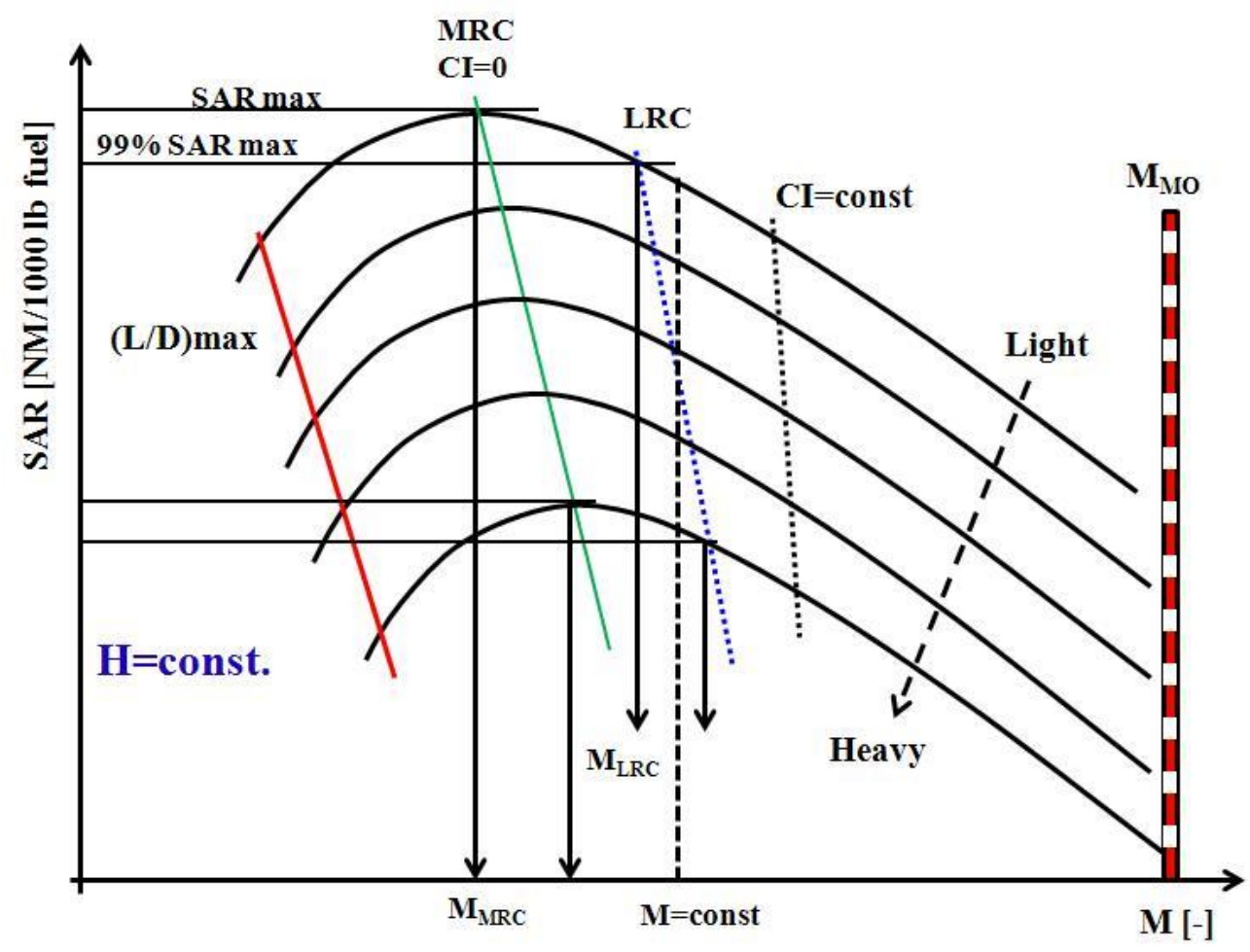

Figure 7. SAR as a function of Mach number for fixed altitude. MRC, LRC, fixed Mach, and fixed-CI speed schedules are illustrated. Not to scale. 


\section{Cruise at LRC}

Normally, jet airplanes will cruise faster than MMrC. Long-range-cruise (LRC) is often used as the industry standard and is arbitrary based on $99 \%$ of the maximum range which gives $\mathrm{M}_{\mathrm{LRC}}$ about 3-4\% faster than $\mathrm{M}_{\mathrm{MRC}}$. In terms of Mach number an increment of M0.01 to M0.02 exists. For example, if $\mathrm{M}_{\mathrm{MRC}}$ is

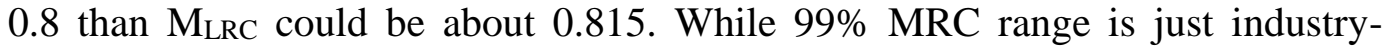
agreed standard resulting in somewhat higher cruising speed, the simple logic behind it is that crew and maintenance time-dependent cost need to be considered when calculating total cost. Time-dependent operational cost is inherently excluded when computing MRC. However, $\mathrm{M}_{\mathrm{ECON}}$ takes accurately into account the total cost (fuel and time-related cost).

\section{Cruise speed controlled by cost-index}

ECON-cruise condition in modern FMS-equipped airplanes covers the speed region basically from below $\mathrm{M}_{\text {MRC }}$ to almost MMO. While MRC and LRC do not account for wind, ECON mode will update flight parameters based on the current wind. No general or fixed CI can approximate LRC mode accurately. Typically, LRC mode implies CI of about 20 to 50 (in 0-200 CI-range FMS) which will vary with altitude and weight. A CI may be obtained scientifically by accurately accounting for all time-dependent and fuel cost (Padilla, 1996). It should not be used solely for speed-control (higher CI implies faster flight). The issue of CI is complicated and will be specifically dealt with in another article.

\section{Discussion of cruise performance}

Cruise performance of subsonic and supersonic (SST) airplane is now discussed. The GC route between the EZE (S034 49' 20" and W058 ${ }^{\circ} 32^{\prime}$ '09'), which is the Buenos Aires International Airport in Argentina (IATA: EZE, ICAO: SAEZ) and the PEK (N040 04' 48" and E1 $16^{\circ} 35^{\prime}$ '04"), which is the Beijing International Airport in China (IATA: PEK, ICAO: ZBAA) is used as an example of the GR flight. Utilizing both Equations 11 and 12 for the orthodrome distance returns exactly the same EZE-PEK GC arc-length of 10,415.3 NM (about 400 NM less than half GC arc-length). Calculations were performed on a 64-bit floating-point CPU to minimize rounding errors. EZE and PEK are not exactly at antipodal points, but very close for this analysis. Although approximately any GC route would do for antipodal points, considering the 180/207/240/330 ETOPS limitations as appropriate for airplane type, the best route is to start NE, overfly Brazil, cross Atlantic ocean fly parallel to the coast of western Africa, skimming north-west Europe and north-western portions of Russia and then after reaching 
maximum latitude over its NW parts "descending" on SE headings over Mongolia to Beijing. The illustration of the GC route is shown in Figure 8. The GC Mapper ${ }^{\circledR}$ was used for graphical presentation and its GC calculator returned the value of GC distance within 2.3 NM of the value obtained here using Equations 11 and 12. Interestingly, the rhumb-line (loxodrome) distance EZE-PEK is 10,713 NM (300 NM longer than orthodrome) on a constant heading of about $65.2^{0}$ and including over 3,500 NM flight over southern Atlantic Ocean.

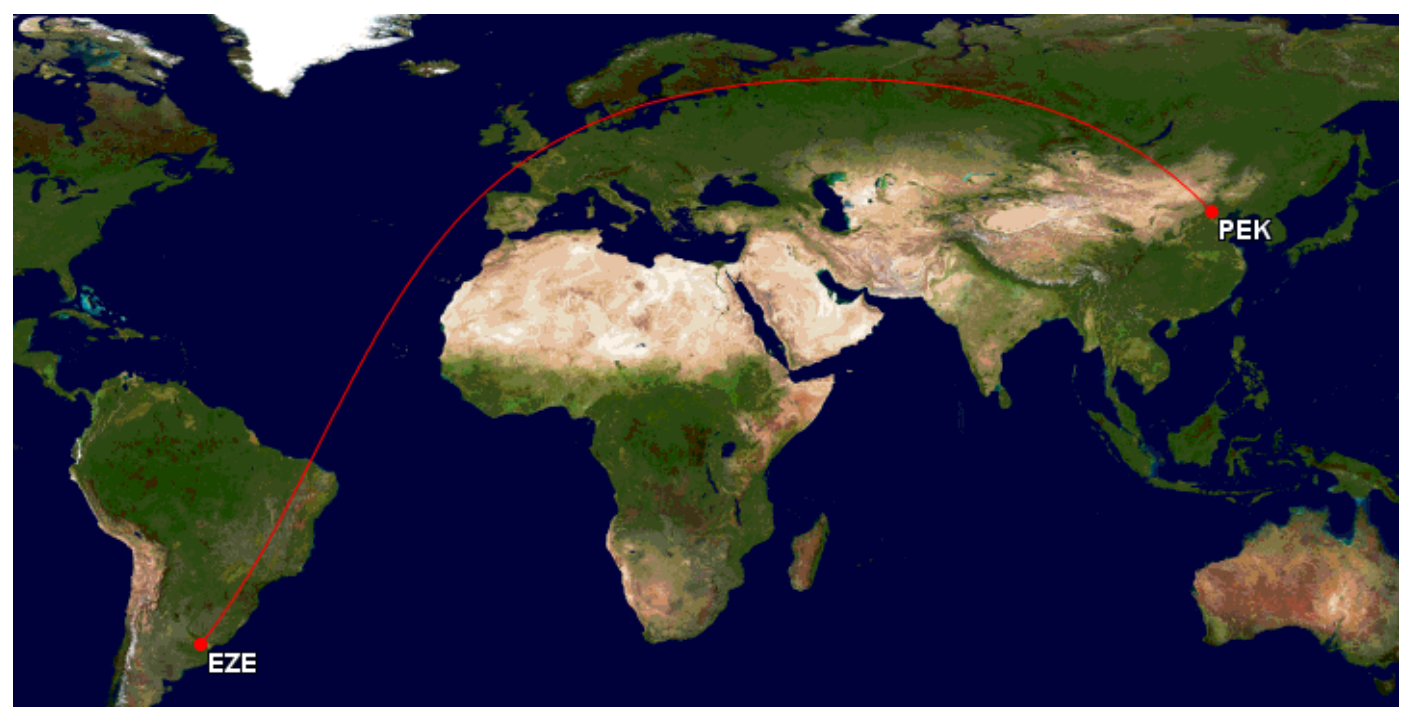

Figure 8. Great circle route EZE to PEK (10,415 NM) on conformal cylindrical Mercator chart. Courtesy of GC Mapper. Maps generated by the Great Circle Mapper (www.gcmap.com) - copyright (C) Karl L. Swartz.

\section{Subsonic aircraft}

Two well-known and successful airframe designs are first used to discuss the range and passenger-miles performance of subsonic aircraft. A wide-body twin-jet ETOPS-certified B767-300ER, that entered service originally in 1988, has the maximum RF of about 12,500 NAM at cruise speed $\mathrm{M}=0.8$. Considering that about $40 \%$ of the MSTOW $(162,000 \mathrm{lb} / 412,000 \mathrm{lb})$ can be in fuel results in the maximum still-air range of about 6,300 NAM. This range can be achieved with about 200 passengers resulting in about 1,260,000 passenger-nautical-miles or about $56 \mathrm{pnm} / \mathrm{g}$ (passenger-miles per gallon). All these computations are estimates in the absence of manufacturer's data. Another very successful airplane design is venerable MD-80 series equipped with the older P\&W engines (JT8D217/219). These were great engines in their own times but $30+$ years have passed since. For example, the maximum-fuel range of MD-83 is about 2,300 NAM with 
135 passengers and $25 \%$ of MSTOW in fuel resulting in about 310,000 passenger-miles or $54 \mathrm{pnm} / \mathrm{g}$. The RF of MD-83 is about 9,500 NAM mostly because of the older engines with SFC of about $0.740 \mathrm{lb} / \mathrm{lb}-\mathrm{hr}(\mathrm{kg} / \mathrm{daN}-\mathrm{hr})$ at optimum altitudes and cruise Mach numbers. The airframe aerodynamics itself was superb for its time with high aerodynamic efficiency $(L / D)$ at high Mach numbers, $(M \times L / \mathrm{D}) \approx 12$. Filippone (2006) gives values of effective aerodynamic efficiency for different subsonic and supersonic airplanes. The best subsonic aerodynamic efficiency $(L / D)_{\max }$ in existing T-category airplanes is in the range of $16 \div 19$ (Filippone, 2006; Nicolai \& Carichner, 2010). For airspeedindependent SFC this will translate into maximum cruising $(L / D)_{c r}=0.866(L / D)_{\max }=14 \div 16$ (Hale, 1984) at a constant altitude (such as in step-climb). Nicolai and Carichner (2010) give $(L / D)_{c r}=0.943(L / D)_{\max }$ since the thrust stays constant and an airplane is in a continuous cruise-climb.

To obtain the global range, a commercial airplane that can fly non-stop $\mathrm{GC}$ route to any location on the planet need to have air range of $11,000+\mathrm{NM}$ while carrying noteworthy amount of payload. To achieve such range with the fuel-ratio of about 0.51 (cruise fuel is $40 \%$ of MSTOW), the RF needs to be larger than 22,000 NAM. In reality, a RF of 24,000 NAM would be more appropriate to achieve SGR of 11,000 NM accounting for wind, GC route deviations, and mandatory fuel reserves. That is RF increase in excess of $40 \%$ from the best current airplane designs. To obtain the ultra-long RFs, the new subsonic airplane designs cruising at Mach 0.90-0.92 and having cruising $(L / D)_{c r}$ in excess of 20 are needed. That would also require modern jet engines with the cruise SFC being no greater than $0.45(\mathrm{lb} / \mathrm{hr} / \mathrm{lb})$ at cruising FLs and Mach numbers with existing JP fuels. Achieving such airframe-engine performance improvements is not going to be easy. It is thus crucial to move the drag-divergence Mach number toward Mach 0.92, and higher, while simultaneously increasing the cruising aerodynamic efficiency. Any airspeed increase beyond the drag-rise Mach number reduces range as the wave-drag starts increasing steeply reducing the aerodynamic efficiency significantly and the small increase in cruising Mach number is simply not worth it.

Besides achieving high effective aerodynamic-efficiency and low engine SFC, the only other way to attain consistent ultra-long ranges in conventional designs is to carry large weight percentages in fuel. This however reduces payload and/or requires low EOWs. To circumnavigate this problem and increase cruise efficiency, designing light-weight airplane structures is essential which will allow $45 \%-55 \%$ of MSTOW to be fuel, $10 \%$ of MSTOW payload, and the rest (35\%$45 \%$ ) in basic operating weight (BOW or EOW). A lot of progress has been done 
in introducing modern composite and sandwich structures (Piancastelli et al, 2013b). Additionally, the new Aluminum-Lithium alloy 2195 with Friction Stir Welding (2195-FSW) represents a viable alternative to CFRP primary structures (Piancastelli et al, 2013a) enabling Aluminum comeback in airplane structures.

As an example, performance calculations have been made for a fictitious future wide-body twin-jet subsonic aircraft design that would meet GR requirements. The MSTOW is $865,000 \mathrm{lb}$ carrying 330 passengers. BOW is $40 \%$ of the MSTOW or 346,000 lb. Total fuel will comprise 50\% of the MSTOW $(432,500 \mathrm{lb})$ with the mission fuel of 47.5\% MSTOW (about 411,000 lb). In order to achieve a 12,500 NAM range this airplane will need to cruise at $M=0.90$ and have minimum cruise efficiency $\left(E_{c r}=L / \mathrm{D}=20\right)$. Required cruise $\mathrm{SFC}$ from the two $140,000 \mathrm{lb}$ turbofans is $0.450 \mathrm{lb} / \mathrm{hr} / \mathrm{lb}\left(I_{S P}=3600 / S F C=8,000 \mathrm{~s}\right)$, which is about $20 \%$ lower than the lowest available figures today (Lee, 2014). Maximum payload is $10 \%$ of MSTOW or 86,500 lb including 330 FAA-passengers (170 lb average passenger) with luggage $(66,000 \mathrm{lb})$ and the remaining $20,500 \mathrm{lb}$ in cargo. Every half-percent in fuel savings or EOW reductions increases payload by 22 passengers. Such airplane would cruise-climb at 515 knots, have mission FWR of 0.475 , weight-ratio of 1.9 , FR of 0.644 , and the RF of 19,500 NAM. In terms of transportation efficiency, such design would deliver almost $70 \mathrm{pnm} / \mathrm{g}$ or about $25 \%$ higher than best designs today. A long-term goal on ultra-long routes is in achieving the transportation efficiency of $75 \mathrm{pnm} / \mathrm{g}$ (or $86 \mathrm{psm} / \mathrm{g}$ ). Substantial future efforts, research, development, and investments will be needed to obtain such figures of merit in engine power/thrust and efficiency, high-subsonic aerodynamics, and light-weight airplane structures and systems. The required cruising aerodynamic efficiency of a future subsonic global-range cruiser is calculated and presented in Figure 9 according to Equation 9 (integrated air-range where SFC is Mach dependent). To achieve the range of 12,500 NAM at Mach 0.9 and $45 \%$ of takeoff weight in cruise fuel (FWR) with SFC $=0.45 \mathrm{lb} / \mathrm{lb}-\mathrm{hr}$, a minimum cruising efficiency of $E_{c r}=23$ is needed.

\section{Supersonic aircraft}

The information on maximum cruise range of supersonic T-category airplanes is naturally scarce. Historically, there was only one successful design of supersonic commercial transport airplane that entered revenue service and that is British-French SST "Concorde". Soviet (Russian) SST Tupolev TU-144 was designed and manufactured (16 aircraft total) and briefly entered the airline service in 1977, but was soon grounded and solely used as a cargo airplane until 1983. Concorde was powered by 4 thrust-by-wire Rolls-Royce/Snecma Olympus 
593 Mk 610 pure turbojets (zero BPR) with SL ISA static thrust of 32,000 lb (dry) and 38,000 lb (afterburner/reheat) each. The SFC of Concorde's Olympus turbojet was almost constant in supersonic range with the value of $33 \times 10^{-6} \mathrm{~kg} / \mathrm{Ns}$ or $1.167 \mathrm{lb} / \mathrm{lb}-\mathrm{hr}$ at Mach 2 (dry power). According to Mair \& Birdsall (1992), the $\mathrm{RF}$ of Concorde was little over $14,000 \mathrm{~km}$ or about 7,600 NAM. Concorde is a large airplane with takeoff weight of about 410,000 lb (187,000 kg MTOM) but it typically only carried 100-110 passengers and a crew of 7-9. The cruise fuel available was about $65,000 \mathrm{~kg}$ or $143,000 \mathrm{lb}$ which was about $35 \%$ of the airplane MSTOW. Maximum fuel load was about $95,000 \mathrm{~kg}(210,000 \mathrm{lb}$ or over $50 \%$ of the MSTOW). Large amount of fuel was needed to reach FL500+ and accelerate, with afterburners assist, through the transonic region up to Mach 1.7 and then reach Mach 2 (actually M=2.02) in dry-power cruise. The aerodynamic efficiency of the "Speedbird" Concorde's highly swept slender delta-wing (ogee double delta) was about 7.50 at Mach 2, resulting in $(M \times L / D)=15$. However, due to high (dry) SFC (twice the SFC of modern high-BPR turbofans), the aircraft maximum operating range was only about $6,500 \mathrm{~km}(3,500 \mathrm{NAM})$. In passengersmiles per gallon that would be only about $15 \mathrm{pnm} / \mathrm{g}$ (385,000 passenger-NM on $170,000 \mathrm{lb}$ of fuel with 1 gallon of jet fuel being about $6.75 \mathrm{lb}$ ). No wonder that Concorde airfares were 5 to 10 times more expensive than using subsonic jets.

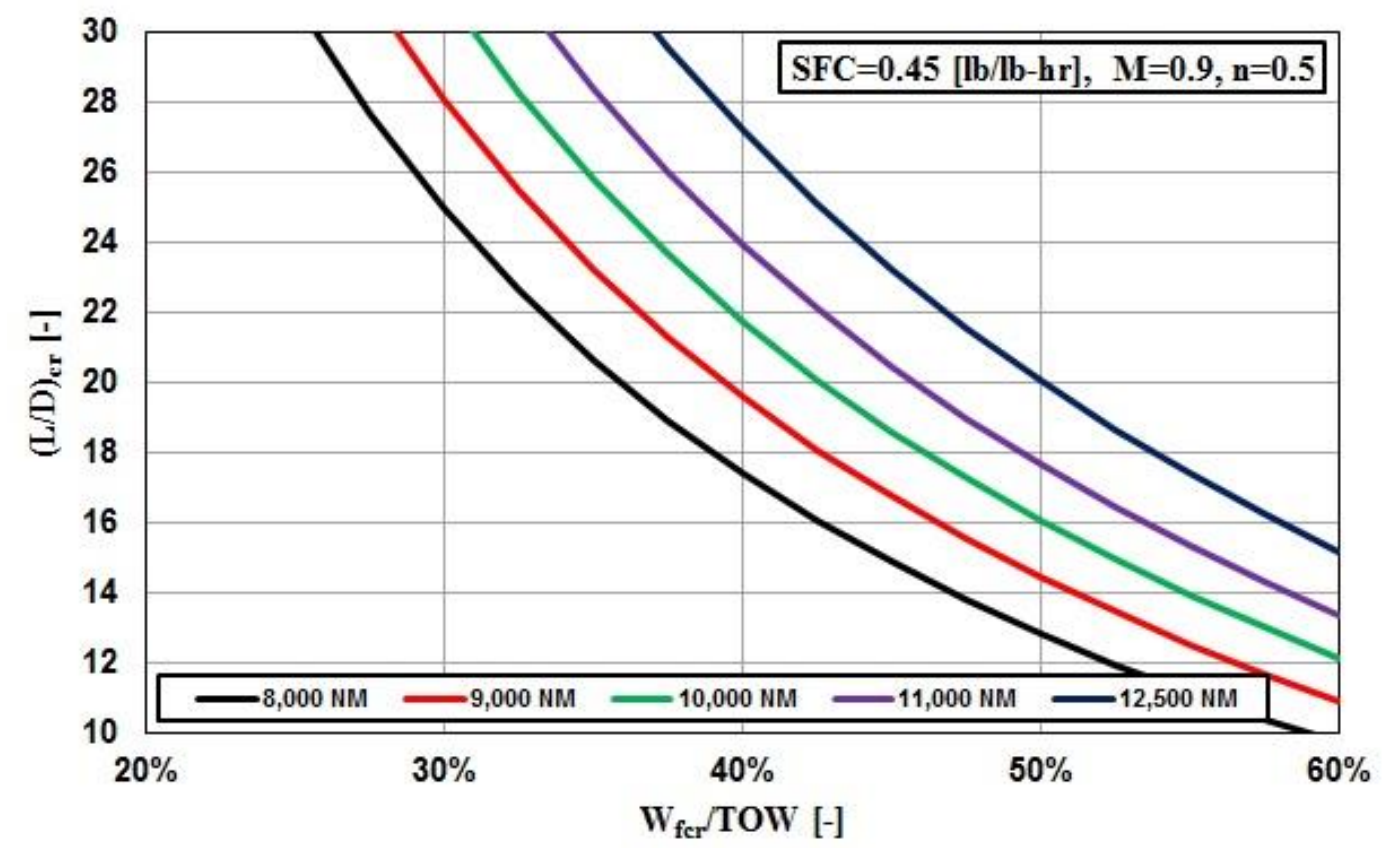

Figure 9. Required cruising aerodynamic efficiency for a future $\mathrm{M}=0.9$ subsonic airplane with low-SFC turbofan engines. 
Considering the subsonic and supersonic $(\mathrm{M}<5)$ speed range there are principally two optimal cruising Mach numbers (Filippone, 2006; Mair \& Birdsall, 1992). One is subsonic and just below the drag-divergence (drag-rise) Mach number. The other optimum Mach number is far on the other side of the transonic region and around Mach 2. An airplane is optimized either to cruise at high-subsonic speed (e.g., $M=0.82$ ) or at the supersonic speed (e.g., M=2). The aerodynamic efficiency of supersonic aircraft decreases because the coefficient of drag which initially "skyrockets" through the transonic region and then gradually decreases to a new value in the supersonic region. Simultaneously, the maximum coefficient-of-lift is basically halved going through the transonic region and deep into the supersonic range (Vinh, 1997). The vortex-drag coefficient increases almost linearly with Mach number (Raymer, 1999; Vinh, 1993) and the aerodynamic efficiency around Mach 2 is less than a half of what it is in highsubsonic region of the modern subsonic jetliners. Essentially, the same Breguet range equation (Equation 4) can be used for supersonic cruise calculations. No attempt is made here to describe any details of the supersonic aerodynamics.

The calculated required aerodynamic efficiency as a function of cruising fuel-fraction for a future $\mathrm{M}=2.4$ global-range supersonic-cruiser with hightemperature turbojet technology and low (dry) SFC (0.8 lb/lb-hr) is shown in Figure 10. Huge efforts will need to be made to double the existing aerodynamic efficiency at increased supersonic Mach numbers, while simultaneously reducing the cruising SFC at FL600 by 50\%. It is not clear how this would be possible with the current understanding of supersonic aerodynamics. Going to even higher Mach numbers will open a completely new set of problems (thermal heating).

It is thus hard to imagine how a supersonic transport (SST) would achieve GR without converting an airplane into the "flying fuel tank" with minimal flight crew. Even then this would seem to be impossible unless drastic reductions in jet engine SFC and doubling of supersonic aerodynamic efficiency is achieved. Due to aerodynamic considerations and thin-wing designs most of the fuel will be stored in a narrow and long fuselage leaving little space for payload. Low-speed handling will be a serious problem. Future hypersonic suborbital flight will have many additional challenges (Daidzic, 2010, 2011).

One benefit of flying at supersonic speeds in stratosphere where the temperature lapse rate is zero is less susceptibility to headwinds. For Concorde, a typical ground speed flying westerly headings at Mach 2 was in the range of 1,050 to 1,150 knots. Flying easterly headings the ground speeds were often 50100 knots faster. For supersonic Concorde flying against 100 knots HW will result in SGR being $92 \%$ of the SAR. For a subsonic aircraft cruising against the 
same HWs will result in SGR being only about $80 \%$ of the SAR (Equation 7). Another crucial advantage of GR supersonic cruiser is the significant reduction of the flight time (e.g., 8 instead of 24 hours for GR). For maximum efficiencies, subsonic airplanes should fly in upper layers of troposphere, supersonic aircraft in upper layers of tropopause, and the future hypersonic cruisers (wave-riders) in upper stratosphere and mesosphere (Daidzic, 2010, 2011).

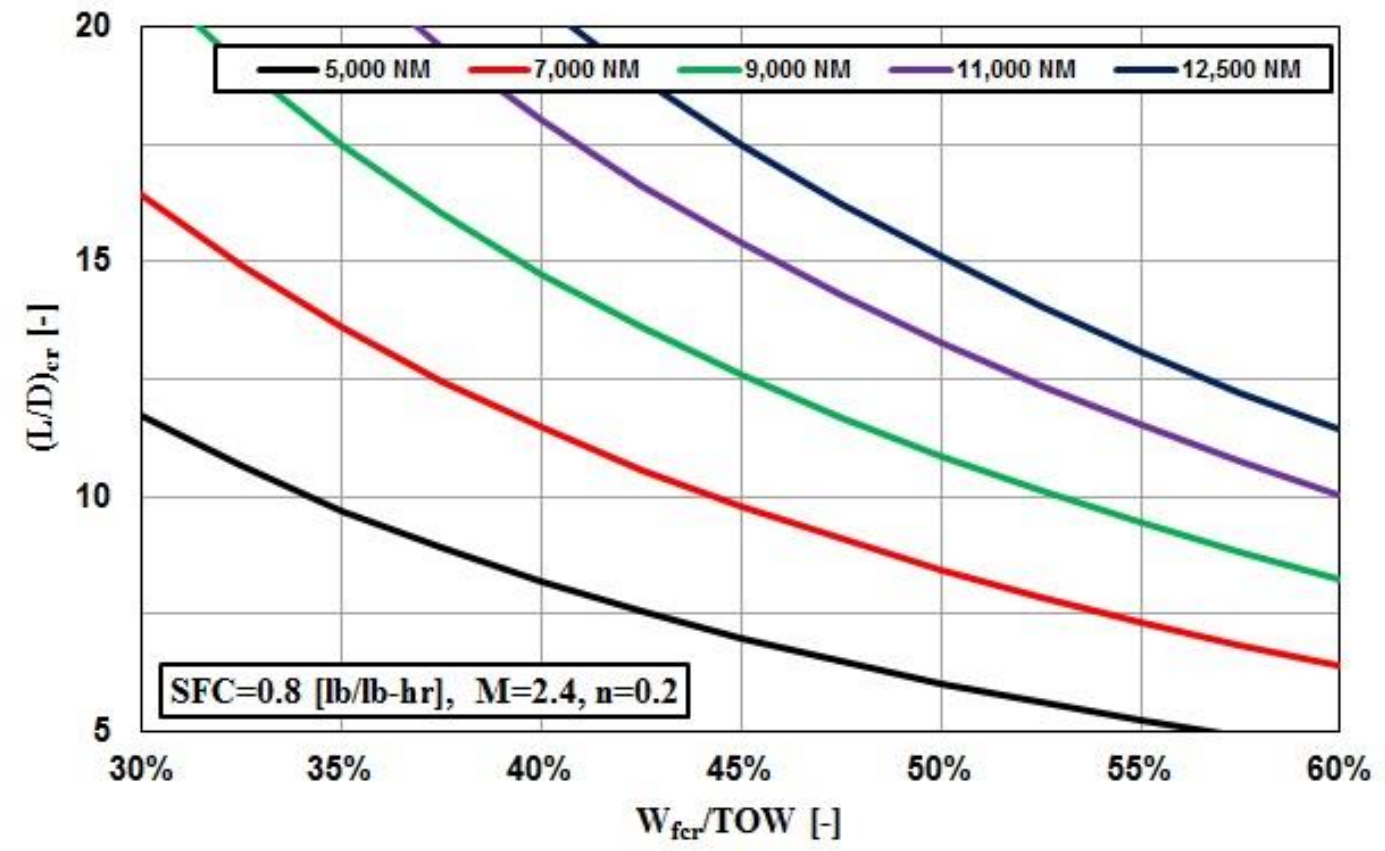

Figure 10. Required cruising aerodynamic efficiency for a future $M=2.4$ supersonic cruiser with the low-SFC turbojet engines as a function of cruising fuel fraction.

\section{Requirements for future global range cruise aircraft}

To summarize, the future GR aircraft will need improvements and advances in several crucial sciences and technologies:

- More efficient subsonic airfoil/wing designs with faster cruising speeds while avoiding wave drag $\left(\mathrm{M}_{\mathrm{DD}} \geq 0.92\right)$ and having MRC efficiency $(L / D>18)$ are needed. A new family of supercritical airfoils and wing geometries will be needed posing a significant challenge. Improved supersonic aerodynamics (supersonic cruising at $L / D>12$ ) incorporating advanced temperature- 
resistant materials allowing supersonic cruise at $\left(\mathrm{M}_{\mathrm{MRC}} \geq 2.40\right)$ is needed. It is not clear how such supersonic aerodynamic efficiency will be achieved.

- More efficient civilian subsonic turbofan engines having lower SFC $(<0.45$ lb/lb-hr) at cruising altitudes with higher overall pressure-ratios ( $\mathrm{PR}>45-50)$, high-temperature turbine technology with $\mathrm{TIT}>1800^{\circ} \mathrm{C}$, improved blade cooling, new single-crystal blade materials, ACC, advanced FADECs, highfrequency active lean-combustion control and active stall and surge control (Jaw \& Mattingly, 2009), better and lighter materials, higher power-to-weight ratios, etc. More efficient turbojets or low-BPR turbofans (BPR < 1) for supersonic cruise ( $\mathrm{SFC} \leq 0.80 \mathrm{lb} / \mathrm{lb}-\mathrm{hr}$ ).

- Research and development in the area of the high-density aviation fuels is important. Increasing the overall efficiency of jet-engine's thermodynamic cycle and even more efficient turbo-machinery is needed.

- Introduction of the lighter aircraft structures, advances in aircraft systems leading to more powerful and lighter components. For example, use of reliable hydraulic systems operating at 5,000 psi and the electrical Variable Speed Constant Frequency (VSCF) wild-frequency AC generators operating at 230VAC with the solid-state high-power electronics using cyclo-converters or DC-link for constant-frequency control could reduce empty weight of future More Electric Airplanes (MEA). Also 270 VDC electrical systems are being explored (Moir \& Seabridge, 2008). High-temperature resistant lightweight structural materials for subsonic and particularly for the supersonic cruisers are needed.

- Stronger and lighter structures for 6,000-ft pressure-cabin standard (Daidzic \& Simones, 2010). This requires the maximum pressure differentials in excess of 10 psi while allowing for altitudes of $50,000 \mathrm{ft}$, and higher, for aircraft in cruise and up to aerodynamic and/or propulsion ceilings, while avoiding the coffin-corner. Supersonic cruisers may be limited to upper tropopause.

It is almost certain that difficult and expensive path to achieving the global range will be evolutionary. Small improvements over many years will lead to a true cost-effective "Globe-Cruiser". It will not be limited by ETOPS and could fly non-stop GC-routes with possible deviations to almost any other place on our planet.

\section{Conclusions}

Immense progress has been achieved in the past 50 years in airframe and jet engine designs. Commercial jetliners of today are reaching still-air cruise distances of 9,000 NM. In order to achieve GR an airplane will have to hold operating maximum air cruise range of about 12,500 NM to account for wind and 
fuel reserves while flying almost half great-circle around the globe or about 11,000 NM distances over ground/sea. Sometimes ETOPS and other airspace limitations may prevent airplanes flying a true great circle. For subsonic airplanes achieving global range that would also imply spending $23+$ hours in an airplane. Supersonic cruisers although traveling quite faster than subsonic airplanes have shorter maximum cruise ranges primarily due to the high SFC of supersonic turbojets. High-temperature turbojet or low-BPR turbofan technology is required to significantly improve supersonic-turbojet's SFC. SSTs also carry relatively small payload-to-weight ratios making such operations expensive. On the other hand, supersonic global-range flights would last only one-third of the corresponding GR subsonic flights. However, despite all the progress made in airplane and engine designs much more will need to be done to achieve the affordable global range. Individual and combined advances and improvements in the area of subsonic and supersonic wing aerodynamics, subsonic and supersonic jet engines, lighter and stronger aircraft structures and systems, high-density fuels, and many other important technologies and innovations which are by no means certain or obvious. The range factor of airplanes achieving global range needs to exceed 20,000-23,000 NAM value with the respective fuel-ratios of 0.644 to 0.545 . This implies that cruise-fuel will comprise about $42 \%-48 \%$ of airplane's MSTOW while enabling for at least $10 \%$ payload-fraction. 


\section{Author Bios}

Dr. Nihad E. Daidzic is president of AAR Aerospace Consulting, L.L.C. He is also a full professor of Aviation, adjunct professor of Mechanical Engineering, and research graduate faculty at Minnesota State University, Mankato. His Ph.D. is in fluid mechanics and Sc.D. in mechanical engineering. He was formerly a staff scientist at the National Center for Microgravity Research and the National Center for Space Exploration and Research at NASA Glenn Research Center in Cleveland, OH. He also held various faculty appointments at Vanderbilt University, University of Kansas, and Kent State University. His current research interest is in theoretical, experimental, and computational fluid dynamics, micro- and nano-fluidics, aircraft stability, control, and performance, mechanics of flight, piloting techniques, and aerospace propulsion. Dr. Daidzic is ATP and "Gold Seal" CFII/MEI/CFIG with flight experience in airplanes, helicopters, and gliders. 


\section{References}

Airbus, Flight Operations Support \& Line Assistance (1998). Getting to grips with cost index, issue II. Blagnac Cedex, France: Author

Allen, J. E. (2003). Quest for a novel force: A possible revolution in aerospace. Progr. Aero. Sci., 39(1). 1-60. doi:10.1016/S0376-0421(02)00049-0

Anderson, J. D. Jr. (1999). Aircraft performance and design. New York, NY: McGraw-Hill.

Asselin, M. (1997). An introduction to aircraft performance. Reston, VA: American Institute for Aeronautics and Astronautics (AIAA).

Bowditch, N. (2002). The American Practical Navigator (2002 bicentennial ed.). Bethesda, MD: National Imagery and Mapping Agency (NIMA).

Daidzic, N. E., \& Simones, M. (2010). Aircraft decompression with installed cockpit security door, Journal of Aircraft, 47(2), 490-504. doi: $10.2514 / 1.41953$

Daidzic, N.E. (2010) Future hypersonic, suborbital, and orbital travel in business aviation, in: Education Session II of the UAA Conference, October 5-7, 2010, Crowne Plaza, St. Paul, MN, USA.

Daidzic, N.E. (2011, September) Designing propulsion systems for future Air/Space transportation, Professional Pilot, 45(9), 82-86.

Daidzic, N. E. (2012, September). Jet engine thrust ratings, Professional Pilot, 46(9), 92-96.

Davies, M. (Ed.) (2003). The standard handbook for aeronautical and astronomical Engineers. New York, NY: McGraw-Hill.

Eshelby, M. E. (2000). Aircraft performance: Theory and practice. Boston, MA: Elsevier.

Filippone, A. (2006). Flight performance of fixed and rotary wing aircraft. Reston, VA: American Institute for Aeronautics and Astronautics (AIAA). 
Hale, F. J. (1984). Introduction to aircraft performance, selection, and design. New York, NY: John Wiley and Sons.

Hill, P. G., \& Peterson, C. R. (1992). Mechanics and thermodynamics of propulsion (2nd ed.). Reading, VA: Addison-Wesley.

Jaw, C. L, \& Mattingly, J. D. (2009). Aircraft engine controls: Design, system analysis, and health monitoring. Reston, VA: American Institute for Aeronautics and Astronautics (AIAA).

Lee, T. -W. (2014). Aerospace propulsion. Chichester, UK: John Wiley \& Sons.

Mair, W. A., \& Birdsall, D. L. (1992). Aircraft performance. Cambridge, UK: Cambridge University Press.

Mattingly, J. D. (2005). Elements of gas turbine propulsion. Reston, VA: American Institute for Aeronautics and Astronautics (AIAA).

McCormick, B. W. (1995). Aerodynamics, aeronautics and flight mechanics (2nd ed.). New York, NY: John Wiley \& Sons.

Moir, I., \& Seabridge, A. (2008). Aircraft Systems - Mechanical, electrical, and avionics subsystems integration (3rd ed.). Chichester, UK: John Wiley and Sons.

Nicolai, L. M., \& Carichner, G. E. (2010). Fundamentals of aircraft and airship design: Volume I - aircraft design. Reston, VA: American Institute for Aeronautics and Astronautics (AIAA).

Padilla, C. E. (1996). Optimizing jet transport efficiency: Performance, operations, and economics. New York, NY: McGraw-Hill.

Piancastelli L., Frizziero L., Zanuccoli G., Daidzic N. E., \& Rocchi I. (2013a) A comparison between CFRP and 2195-FSW materials for aircraft structural designs, International Journal Heat \& Technology, 31(1), 17-24.

Piancastelli L., Frizziero L., Rocchi I., Zanuccoli G., \& Daidzic N. E. (2013b) The "C Triplex" approach for CFRP airliners bodies, International Journal Heat \& Technology, 31(2), 51-60. 
Raymer, D., P. (1999). Aircraft design: A conceptual approach (3rd ed.). Reston, VA: American Institute for Aeronautics and Astronautics (AIAA).

Saarlas, M. (2007). Aircraft performance. Hoboken, NJ: John Wiley \& Sons, Inc.

Sinnott, R. W. (1984). Virtues of the haversine. Sky and Telescope. 68(2), 159.

Treager, I. E. (1996). Aircraft gas turbine engine technology (3rd ed.). New York, NY: Glencoe, McGraw-Hill.

Underdown, R. B., \& Palmer, T. (2001). Navigation: ground studies for pilots. 6th ed. Oxford, UK: Blackwell Science, Ltd.

US Department of Transportation, Federal Aviation Administration. (2008). Extended operations (ETOPS and Polar operations) (Advisory Circular AC 120-42B). Washington, DC: Author.

US Department of Transportation, Federal Aviation Administration. (2013). Part 25, Airworthiness Standards: Transport Category Airplanes. Washington, DC: Author.

US Department of Transportation, Federal Aviation Administration. (2014). Part 121, Operating Requirements: Domestic, Flag, and Supplemental Operations. Washington, DC: Author.

Vinh, N. X. (1993). Flight mechanics of high-performance aircraft. Cambridge, UK: Cambridge University Press.

Wagenmakers, J. (1991). Aircraft performance engineering. New York, NY: Prentice Hall.

Ward, T. A. (2010). Aerospace propulsion systems. Singapore, Singapore: John Wiley \& Sons (Asia) Pte Ltd.

Williams, E. (2011). Aviation formulary V1.46. Retrieved from http://williams.best.vwh.net/avform.htm.

Wolper, J. S. (2001). Understanding mathematics for aircraft navigation. New York, NY; McGraw-Hill. 